\title{
Psychological Wellbeing among Psychiatry Residents: Dealing with Stigma Starts from Our Home
}

\author{
Cipta, D.A. ${ }^{1,2}$, Lalenoh, L. ${ }^{1} \&$ Saputra, $A .^{1}$
}

\begin{abstract}
Introduction: Empathy is the most essential skill to be cultivated during psychiatric training and stigma is the antithesis. While the psychiatry department is perceived to be a place where empathy abounds, several pieces of evidence show the contrary reality.
\end{abstract}

Methods: The authors reflect on the training experience using Kolb's experiential learning cycle framework. PubMed, Google Scholar, and EMBASE search using term "psychiatry trainee stigma", "psychiatry trainee wellbeing", "resident wellbeing", "psychiatry trainee burnout", and "resident counselling", with abstract and full-text reviewed during the conceptualization of the paper.

Results: Literature showed that some psychiatry trainees at several different centres feel uncomfortable to disclose their mental health issues. It is recommended for the psychiatry department counselling team to have affiliation with non-faculty psychiatrists to facilitate the helping process. Some identified causes were burnout, poor intergenerational and intercultural communication. Improving self-care, resiliency, and the whole system to create a stigma-free environment were seen as necessary.

Conclusion: Mutual reflection and collaborative attitude among staff and residents are essential to improve creativity and well-being. This will have a further impact on an empathic service towards patients and the community.

Key words: Stigma, Psychological well-being, Resident counselling, Burnout and Inter-generational differences

\section{Introduction}

As a psychiatrist, dealing with patients requires specific skills to maintain the therapeutic alliance. Empathy is one of the most vital skills for a psychiatrist and a meaningful instrument of therapy in daily practice. Psychiatry training programmemes bring opportunities that help psychiatry trainees learn how to cultivate empathy.

${ }^{1}$ Department of Psychiatry, Faculty of Medicine, Universitas Indonesia, Indonesia.

${ }^{2}$ Usher Institute, University of Edinburgh, Scotland, United Kingdom.

Corresponding Author: Darien Alfa Cipta

Department of Psychiatry, Faculty of Medicine, Universitas Indonesia, Indonesia.

Email: darien.cipta.dc@gmail.com
However, improving empathy is not without its challenges. Stigma, the antithesis of empathy, is the most prominent obstacle in developing human connectedness. Stigma starts to develop when individuals see the quality of others, often the negative, ahead of the individual's figure as a whole person.

It is based on the fear that those who are being stigmatised might behave in different norms and unpredictable ways (Harrison et al., 2018). As Jeffrey A. Lieberman, the past president of the American Psychiatric Association wrote in his book, 'the end of stigma is the future of psychiatry (Lieberman \& Ogas, 2015).

Stigma is defined as "any attribute, trait or disorder that marks an individual as being unacceptably different from the 'normal' people with whom he or she routinely interacts, and that elicits some form of community sanction".

DOI: http://doi.org/10.4038/seajme.v14i1.231

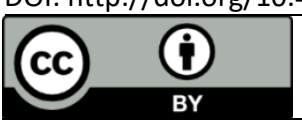

SEAJME. This is an Open Access article distributed under the terms of the Creative Commons Attribution License (http://creativecommons.org/licenses/by/4.0/), which permits unrestricted use, distribution, and reproduction in any medium, provided the original author and source are credited 
There are four components and stages of stigma. The first stage, labelling, starts when stigmatised individuals are noticed as conveying a notable difference from the rest of the others. The next stage is stereotyping, where the linkage of the differences to undesirable characteristics takes place. The third stage is a separating process, in which the categorical distinction between the mainstream group and the labelled group come off. Ultimately, stigmatised individuals undergo a discriminating process characterised by devaluation, rejection, and exclusion (Gelder et al., 2012).

\section{Rationale}

The psychiatry department is perceived by common sense as a place where empathy abounds. Nevertheless, several studies have demonstrated some evidence that is contrary to the above. In Canada, more than 30\% of psychiatry residents had experienced a mental disorder, and stigma was counted as a barrier for disclosure and help-seeking (Hassan et al., 2016). According to two surveys of US Psychiatry Programme Directors, "emotional illness" is a commonly reported reason for resident attrition (Lawson, 2017). In India, 37\% of psychiatry residents in a tertiary care centre stated that stigma is "very much there, even here". Moreover, $72 \%$ felt that they did not feel comfortable disclosing their mental health issues within the department because of concerns about stigma (Raghuraman et al., 2018).

These findings may indicate that stigma in a psychiatry training programme is associated with low psychological wellbeing among residency, which is defined as a sense of life satisfaction, feeling that one is living in accordance with deeply valued and engaged in life fully. For a trainee there are three factors that are strongly related, which are autonomy, competence building, and social relatedness (Raj, 2016). The purpose of this study is to address these issues adequately.

\section{Methods}

The first and second author reflect on their training experience using Kolb's experiential learning cycle framework (Thuente \& Batteson, 2018). During conceptualizing this article, the authors searched from PubMed, Google Scholar, and EMBASE with keywords such as "psychiatry trainee stigma", "psychiatry trainee wellbeing", "resident wellbeing", "psychiatry trainee burnout", and "resident counselling".

\section{Results}

There are several possible causes of stigmatisation in postgraduate psychiatry training. Burnout has been identified as a significant concern which leads to compassion fatigue (Boscarino, 2010). When residents and faculty members have burnout, it is more likely for them to see the illness or negative quality ahead of the person. Faculty members might not be aware of the residents' mental health because of tedious professional demands. At the same time, it is common that in low and middle-income countries, the faculty-trainee ratio is not ideal. Studies have shown that the failure of the system contributed to $80 \%$ of burnout factors (Moffic, 2019). Furthermore, in a cross-sectional study in Singapore, burnout had also been associated with higher stigma in residents' help-seeking behaviour and was related to environment and learner factors including stigma, resilience, and coping mechanism (Chew et al., 2019).

Other factors to be taken into account are the cultural and inter-generational differences. These factors may be responsible for disagreement among residents and faculty members. The generational difference could mean a lot in the training process (Waljee et al., 2018). For instance, hierarchy in the system is unpreferred as millennials favour a flat organisational structure. Traditional metrics to measure one's training progress are also considered to be not as important as personal goals and purposes. For example, developing an intellectual property or launching a healthcare start-up is considerably more principal for millennials than gaining absolute score in the formal examination. When these issues are overlooked, it becomes easy for over expectations to occur, and disagreements develop.

Stigmatisation can also be the consequence of diagnostic label misuse in daily language, particularly when used to describe members of the training programme. Improper use of such labels may malign certain behaviours deemed inappropriate by specific individuals or groups. It conveys a message that "there is something wrong with you" and is potentially harmful ('“She's OCD!' 'He's Schizo!' How Misused Health Lingo Can Harm," 2014). The fear of being labelled in a psychiatry postgraduate training setting is not unfounded. Though one may put a high expectation towards faculty members, psychiatrists have their own biases and stigmas towards mental illness. This leads to a negative attitude towards openness due to 
the fear of being evaluated harshly or losing academic status (Brenner et al., 2018).

An important aspect in dealing with residents who have a mental illness or psychological distress is impartiality. This stance is intricate for faculty members, especially for those who have a role in assessing the residents. The programmeme director is suggested to keep this boundary intact while ensuring the residents with particular difficulties have adequate resources to cope. In an ideal setting, it is wiser to refer to a psychiatrist who is not a member of the faculty for counselling or psychotherapy. Treatment could also be performed by senior faculty members who have a limited role in giving an academic assessment. When a resident finds it challenging to catch up with the standard curriculum, it is best to provide an individual educational plan. It is also advisable to clarify to all members of the programmeme that no diagnosis nor any label automatically disqualifies someone from being a successful psychiatrist, and reduce stigma and harm towards struggling residents. Personal illnesses and struggles often lead to an outstanding career as a psychiatrist later (Brenner et al., 2018).

\section{Conclusion and Recommendations}

Some thought is needed to reduce stigma in postgraduate psychiatry training settings that promote mental health wellbeing for all. For example, self-care training is advisable to prevent burnout for residents, juniors and seniors alike. Faculty members are also encouraged to share practical strategies to cope with burnout that they have learned through experience. Mutual reflection is also necessitated to manage disagreements in an open and label-free learning atmosphere. Improving the system that contributes to the problem entails collaboration from all parties.

The benefits of recognising stigma in the postgraduate psychiatry training are enormous. By eradicating stigma, we may enhance empathy for future psychiatrists. A stigma-free environment in the psychiatric department, the "home" where the entire psychiatry training programmeme takes place, creates a sense of safety and improves collaboration between residents and faculty members. This safe atmosphere will promote creativity and strengthen the educational process of the programmeme. Furthermore, by encouraging mutual reflection, residents will be exposed to reflective clinicians, and this could translate into shared-decision making in doctor-patient context. Eventually, eradication of stigma will improve the quality of service towards patients, and it starts from our "home". It is hopeful that through this literature review and authors' training experience, a collaborative quality improvement will commence and sustain.

\section{Conflict of Interest}

The authors declare no conflict of interest.

\section{Acknowledgement}

We thank our teachers Natalia Widiasih, MD (Psych) and Kristiana Siste, MD (Psych) for the valuable guidance and opinions during the writing of the manuscript. We also thank Robin Ramsay, MD, MRCGP and Professor Christopher Dowrick, MD, FRCGP for their kind review of the paper.

\section{References}

Boscarino, J.A., Adams, R.E. \& Figley, C.R. (2010) Secondary Trauma Issues for Psychiatrists. The Psychiatric Times, 27, 11, p. 24.

Brenner, A.M., Balon, R., Guerrero, A.P., Beresin, E.V., Coverdale, J.H., Louie, A.K. \& Roberts, L.W. (2018) Training as a Psychiatrist When Having a Psychiatric Illness. Academic Psychiatry, 42, 592-597

Chew, Q.H., Ang, L.P., Tan, L.L., Chan, H.N., Ong, S.H., Cheng, A., Lai, Y.M., Tan, M.Y., Tor, P.C., Gwee, K.P. \& Sim, K. (2019) A cross-sectional study of burnout and its associations with learning environment and learner factors among psychiatry residents within a National Psychiatry Residency Programmeme. BMJ open, 9, 8, p.e030619.

Geddes, J.R. and Andreasen, N.C., 2020. New Oxford Textbook of Psychiatry. Oxford University Press, USA.

Moffic, M. (2019) Burnout and the Self-Disclosure of Psychiatrists. Available at: https://www.psychiatrictimes.com/view/whenoaths-are-broken-call-action

Harrison, P., Cowen, P., Burns, T. \& Fazel, M. (2018) Shorter Oxford Textbook of Psychiatry. Oxford University Press, New York.

Hassan, T., Tran, T., Doan, N., Mazhar, M., Bajaj, N., Munshi, T., Galbraith, N. \& Groll, D. (2016) Attitudes of Canadian Psychiatry Residents if Mentally III: Awareness, Barriers to Disclosure, and Help-seeking Preferences. Canadian Medical Education Journal, 7, 2, pp.e14. 
Lawson, N.D. (2017) Structural Stigma and Discrimination against Medical Students and Residents with Suspected Mental Disorders, in: $8^{\text {th }}$ International Together against Stigma Conference. Copenhagen, Denmark. pp. 1-28.

Lieberman, J.A. (2015) Shrinks: The Untold Story of Psychiatry. Hachette, UK.

Raj, K.S. (2016) Well-being in Residency: A Systematic Review. Journal of Graduate Medical Education, 8, 5, pp. 674-684.

Raghuraman, B.S., Nataraj, M. \& Shiva, L. (2019) Psychiatry Trainee Stressors in a Postgraduate Psychiatry Training Centre in India. BJPsych International, 16, 3, pp. 53-55.
"She's OCD!" "He's Schizo!" How Misused Health Lingo Can Harm (2014). NBC News.

Thuente, L.F. \& Batteson, J.T. (2018) Kolb's Experiential Learning Theory as a Theoretical Underpinning for Interprofessional Education. Journal of Allied Health, 47, 1, pp. 3-8.

Waljee, J.F., Chopra, V. \& Saint, S. (2020) Mentoring Millennials. Jama, 323, 17, pp. 1716-1717. 